\title{
Adverse Health Effects of Mercury Use on Illegal Gold Miners: A Study in Garasi, Eritrea
}

\author{
Milkias Haile $^{1, ~ *}$, Omer Hussein ${ }^{2}$, Yohana Haile ${ }^{1}$ \\ ${ }^{1}$ Department of Pharmacy, Halibet National Referral Hospital, Asmara, Eritrea \\ ${ }^{2}$ Department of Pharmacy, Azel Pharmaceuticals, Keren, Eritrea
}

Email address:

milkiashaile29@gmail.com (M. Haile)

*Corresponding author

\section{To cite this article:}

Milkias Haile, Omer Hussein, Yohana Haile. Adverse Health Effects of Mercury Use on Illegal Gold Miners: A Study in Garasi, Eritrea. Advances in Biochemistry. Vol. 5, No. 2, 2017, pp. 16-21. doi: 10.11648/j.ab.20170502.11

Received: February 24, 2017; Accepted: March 25, 2017; Published: April 13, 2017

\begin{abstract}
In recent years, an increase in the activities of illegal gold mining was seen in many provinces of Eritrea. One of such provinces is Garasi where this case study was done to determine its adverse effects on health of miners. This study was based on survey using questionnaire with personal interview of illegal miners at the site of their work. Using snowball sampling method, a total number of 50 miners were interviewed out of which two were females. The age of illegal miners was ranged from 11 to $>50$ years with work experience of 5 to 8 years. Majority of the miners claimed that they use mercury in the process of amalgamation. Miners experienced many health complications i.e., cough, chest pain, weakness, stress, insomnia, excessive salivation etc. after exposure to mercury. For some miners it was found that the mercury exposure was as many as 20 times per year. Chronic exposure to mercury increases adverse effects to health, in this study two miners who had an experience of 12 years showed the associated symptoms of chronic exposure. Out of 50 illegal miners, 41 visited outreach health facility to seek relief from the symptoms in which $53.6 \%$ reported that they did not get any relief from their symptoms. The most common diagnosis and treatment among the illegal miners was pneumonia. In conclusion the effects of this poisoning may increase with the coming years; this activity is relatively at its infancy stage, with an increase in the associated damage in human health, animal life and the environment. Health sectors need to launch awareness campaigns aimed at educating miners about the dangers of mercury to health. And to seek alternative methods before the damage to health and other environmental damage escalates.
\end{abstract}

Keywords: Illegal Gold Mining, Illegal Gold Miners, Mercury Poisoning, Eritrea

\section{Introduction}

The scarcity of gold relative to other metals and the efforts exerted to mine it has made gold a highly precious metal. [1, 2] However the human cost of gold beginning from its mining-extraction, refining, and marketing -to its accumulation is rife with unhealthy and degraded living conditions and shortened life span. [3]

One way to increase the yield of mined gold is to use mercury to amalgamate it. However mercury is a known poison and exposure to it causes many adverse health effects. Contamination is reflected by elevated mercury concentrations in hair, urine, blood, and other tissues. Nevertheless clinical evidence of mercury poisoning is lacking; only a few studies actually detected symptoms of poisoning. [4]

In places where illegal gold mining is prevalent, tons of mercurial waste is discarded in the environment. For example fifteen tons of gold are extracted from the Madre de Dios region per day, meaning that as much as 42 tons of mercury are left behind daily due to illegal gold mining, which remains in the environment for many years. [5] Studies have shown that for every kilo of gold produced, an estimated 1.3 $\mathrm{kg}$ of mercury are released into waterways, polluting water, aquatic organisms and human populations that consume water and fish. [6]

Mercury use is common among the illegal miners due to its availability and inexpensiveness. Therefore its use is likely to continue despite its hazards to human health and 
destruction of environment. For example in the Philippines little appears to have been accomplished by attempts to educate miners about mercury's hazards or by regulations concerning its use as long as the price of gold makes extraction and processing economically viable. [7]

Many of the people who participate in illegal gold mining understand mining as an activity that does not require any educational background or sophisticated equipment. This perception along with increasing gold prices motivates an increased participation in illegal gold mining. An increased demand with a relatively decreased supply has pushed gold prices up by $18 \%$ in the years $2000-2010$ with $360 \%$ total increase over the decade. [8]

Additionally self-employment and the absence of age constraint on such undertakings promote further participation from all age ranges. These clandestine activities aside from being illegal and without having the proper mining permissions are of great hazard to the health of miners. This is mainly because the miners use mercury-generally without any basic protective gear for the workers. During processing powdered ore is mixed with mercury to create an amalgam that miners burn to evaporate the mercury and collect the gold.

Miners exposed to mercury on a regular basis show adverse neurological effects, the most common symptoms being reduced motor skills, poor concentration and depression, aggressiveness, problems with hearing and sight, and taste. [6] This process is detrimental to children as exposure to mercury can cause developmental and neurological problems. [9] Mercury may be ingested (accidentally during work or when it contaminates water), absorbed through the skin (when it is handled with bare hands or miner shave to swim in mercury contaminated water), or inhaled (when the mercury is burnt off of pieces of gold). [6] This can result in inflammation of vital organs, the inability to urinate, shock, and death. It can also result in skin lesions, irritation to the lungs, difficulty breathing, and permanent damage to the nervous system. [10] On-going mercury contamination in Madre de Dios directly contributes to nerve damage and shorter life expectancies for active miners. It also directly affects members of the community who suffer from eating local fish with high mercury levels. [11]

In recent years, in many Eritrean provinces an expansion in the illegal gold mining activities was observed. This study was conducted in one of such provinces, Garasi, a very hot area found $50 \mathrm{~km}$ west of Sheib (a sub region on northern red sea). It is a mountainous area with no transportation and telecommunication access. Almost all $(90 \%)$ of the miners live near the mining site. Miners go to the site on foot and use camels for transporting food and other necessities.

The concept behind this study is mercury use by miners is a dire problem that has not gotten any attention from the health sectors and the miners has no knowledge about the risks associated with their occupation. In addition no prior study was done that focuses on this particular aspect of the recent mining boom.

\section{Objective of Study}

1. To access the risk of mercury use on illegal gold miners in Eritrea.

2. To give an insight to the miners about the health hazards associated with mercury use and to raise awareness on the health sectors about this rapidly escalating concern.

3. To establish preliminary work on this issue for further studies.

\section{Methodology}

This is a preliminary study done on 50 subjects who participate on illegal gold mining. It's the first study of its kind done in Eritrea that specifically addresses the issue of health in illegal gold mining. The data collection method used was snowball sampling method. This method was utilized because these illegal miners have fear of governmental retribution and sometimes data collectors were met with distrust as government agents that have come to collect information. The number of participants was much lower than the total number of population who practice illegal mining activity for the stated reason. Most of the miners were unwilling to reveal themselves. Verbal consent was received from the miners before the start of data collection and for the underage participants permission was granted by a guardian or a parent.

Inclusion and exclusion criteria

Every consenting miner who participates in this mining activity was included in the study. And we exclude those underage miners that we couldn't get permission from their guardians.

A questionnaire was prepared in native language (Tigrinya). The researchers conducted the interview and filled the questionnaire. The responses were later translated to English.

A questionnaire that included;

1. The age of miners

2. The sex of miners

3. Years worked as a miner

4. Whether they used mercury as a mining tool

5. The health problems they have developed since they started working in the mining sites

6. Whether miners have visited a health centre for their complaints etc.

Was used to collect data from the respondents.

Study variable

Independent variable

1. Age of the miners

2. Sex of the miners

3. Marital status of the miners

4. Residence of the miners

Dependent variables

1. Years worked as a miner.

2. Frequency of mercury exposure in a year.

3. The health problems they have developed since they start working on the site.

4. Whether the miners visit health facility or not. 


\section{Results and Discussions}

Majority $(80 \%)$ of the miners interviewed used mercury as a reagent (figure 1 ). The remaining $20 \%$ of the miners do not use mercury or any other chemicals when processing the gold. During burning, the elemental mercury evaporates and is inhaled by miners leading to many of the symptoms associated with mercury inhalation and many that are seen in the case subjects. Unfortunately mercury use is common in many regions where illegal and small scale gold mining is found. Some years ago the total number of gold miners in the world using mercury amalgamation to produce gold ranged from 3 to 5 million, including 650000 from Brazil, 250000 from Tanzania, 250000 from Indonesia, and 150000 from Vietnam. [12]

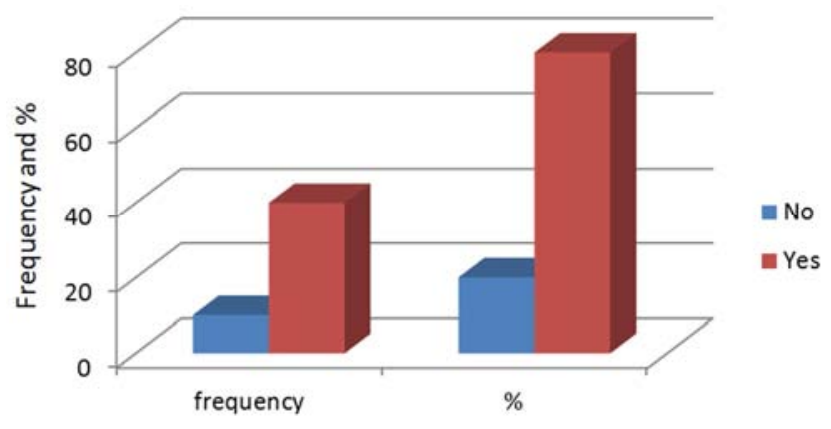

Figure 1. Use of mercury for mining.

The health risks associated with mercury poisoning depends upon the frequency of exposure. Metallic mercury which is largely excreted as mercuric mercury has a varying excretory half-lives depending on the organ of deposition and redox state, with values ranging from a few days to several months, with some deposits (e.g., CNS) having a half-life surpassing several years. Consequently high exposure frequency leads to chronic poisoning with the accompanying health complications. Many of the miners though they suffer from various health complications mentioned below, continue working in the mining sites. Some miners admitted to an exposure of more than 20 times per year (Table 1).

Table 1. Mercury exposure per year.

\begin{tabular}{lll}
\hline Exposure/year & Frequency $(\mathbf{n}=\mathbf{5 0})$ & $\mathbf{\%}$ \\
\hline $1-5$ & 6 & 6 \\
$6-10$ & 11 & 22 \\
$11-15$ & 9 & 18 \\
$16-20$ & 1 & 2 \\
$>20$ & 2 & 4 \\
Not certain & 21 & 42 \\
\hline
\end{tabular}

Due to recent booming in illegal mining activity in Eritrea, almost half of the miners i.e. $n=22$ worked for $1-2$ years at the mining sites (Table 2). Compared to those who have been immersed in this type of work long, this group have relatively less health complaints. With the highest complaints coming from those who have worked for more than five years. This group reported that symptoms like dyspnoea, chest pain and insomnia was severe and frequent compared to those who worked for less than five years. A study conducted in Indonesia found that those that worked in mining sites for greater than two years are three times more at risk to experience symptoms of health problems than miners who work for less than two years, gold miners with more than ten years of experience show $90.9 \%$ mercury poisoning. [13]

Table 2. Work experience in years of miners.

\begin{tabular}{lll}
\hline Years of work on site (in years) & Frequency & \% \\
\hline $1-4$ & 22 & 44 \\
$5-8$ & 23 & 46 \\
$9-12$ & 3 & 6 \\
$>12$ & 2 & 4 \\
\hline
\end{tabular}

The miners complained of weakness (94\%), weight loss $(76 \%)$, dyspnoea $(72 \%)$ chest pain $(68 \%)$, cough $(56 \%)$ etc. Metallic taste was observed in $38 \%$ of the miners; may be due to dust inhalation during grinding and crushing of the stones. About $20 \%$ miners complained of insomnia. It is known that mercury exposure in the brain causes sleep disturbance. Gingivitis was seen in four workers who used mercury to remove plaques (figure 2).

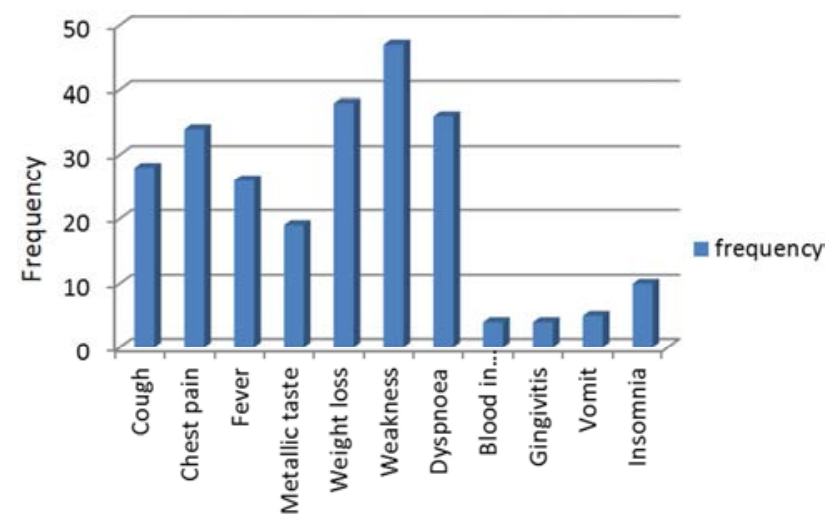

Figure 2. Distribution of symptoms among miners.

When asked during the interview the miners did not associate the symptoms such as cough, chest pain, fever, weakness, etc. could be due to the use of mercury. Most $(82 \%)$ of the workers reported that they visited a health facility (Figure 3) after experiencing the above symptoms (figure 2). However, none of them told that they were diagnosed with mercury poisoning, with the most common diagnosis being pneumonia and others like common cold, bronchitis, malaria, gastric ulcer, dengue fever and hypertension. Seven of the subjects reported that they did not know what they were diagnosed with. The researchers made a visit to the health facility to make sure whether these subjects were diagnosed with mercury poisoning or not. No data regarding mercury poisoning was recorded at the facility level(Table 3).Treatment received by miners at those health facilities was according to the diagnoses. Those who did not feel any relief from the received treatment made a repeat visit to the health facilities, sometimes to be given the same treatment as their earlier visits. It should be noted that most of them visited an outreach health facilities that do not have 
any sophisticated lab equipment that can conclusively diagnose mercury poisoning, apart from that the personnel in those facilities rarely includes medical doctors. In addition, the probability of diagnosing the poisoning is considerably higher when proper patient occupational history is taken, but for legal reasons those miners do not disclose such information willingly on their visits. Moreover, mercury poisoning does not have any specific symptoms resulting in misdiagnosis of the poisoning.

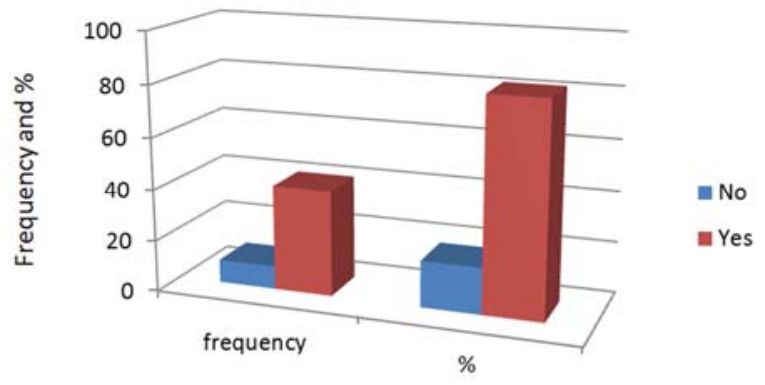

Figure 3. Miners that visited a health facility.

Table 3. Common diagnosis.

\begin{tabular}{ll}
\hline Diagnosis & Frequency \\
\hline Pneumonia & 23 \\
Common cold & 3 \\
Bronchitis & 3 \\
Malaria & 2 \\
Gastric ulcer & 1 \\
Dengue fever & 1 \\
Hypertension & 1 \\
Do not know & 7 \\
\hline
\end{tabular}

Out of the $82 \%$, miners who visit the health facilities $46.4 \%$ reported recovery from their symptoms. Here it should be noted that it does not necessarily mean these subjects recovered from mercury poisoning. It is possible that additional to the poisoning they may have had other diseases and treated accordingly. The remaining 53.6\%said that they saw no difference (Table 4).

Table 4. Miner's recovery after health visit.

\begin{tabular}{lll}
\hline Recover & Frequency & \% \\
\hline No & 22 & 53.6 \\
Yes & 19 & 46.4 \\
\hline
\end{tabular}

Most of those miners live near the mining sites with their families: in constant contact with mercury. This increases considerably the risk of mercury contamination both from direct exposure by inhalation during processing and indirectly from the environment. Out of all the cases, 50\% of the subjects reported a termination of symptoms when they leave the area of work and $34 \%$ reported that they experience abating of some of the above symptoms. While a small number of the miners $16 \%$ claim that there was no desisting of the symptoms even after they leave the area of exposure (Figure 4). This may mainly be due to the high levels of mercury in their body and a temporary leave does not make a remarkable decrease as to relieve them from their symptoms.

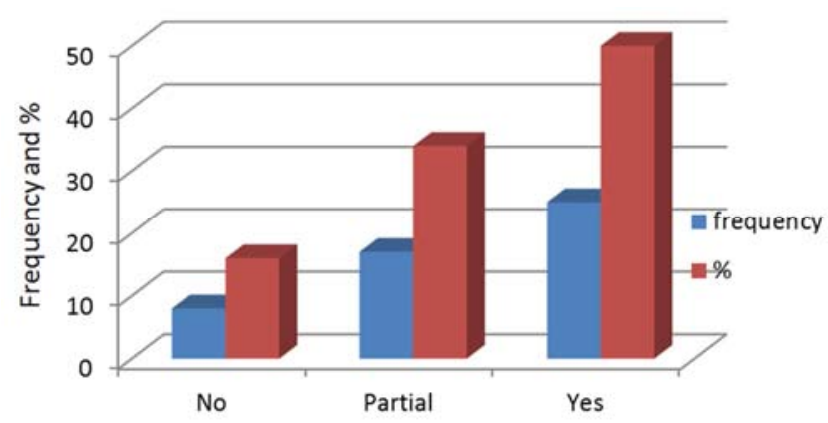

Figure 4. Termination of symptoms after leaving mining site.

Aside from many of its social welfare hazards like damage to health, land disputes, violence among miners, arguably the most troubling fact of this illegal gold mining is the age of the people that participate in the activities. In this study we found that youngsters aged 11-20 were 11 out of the 50 study subjects (figure 5). Although they are not the highest numbered group, still it needs urgent attention. The increased number could be due to the fact that the continuous increase in gold prices motivates the young age group to abandon their studies and to participate in these activities. The International Labour Organisation (ILO) notes that about $20 \%$ of children engaged in small-scale mining work for adults who are not their parents. [14] Due to the extremely hazardous nature of the work, mining is considered a Worst Form of Child Labour (WFCL). Children are commonly used to enter mine shafts too narrow for adults, or are tasked with cleaning gold using mercury.[15] Mercury poisoning can cause a variety of serious health effects for children. It attacks the central nervous system and can cause developmental and neurological problems.

In the study the highest number of subjects involved in this illegal mining activity are aged $41->50$ i.e. 14 out of the 50 miners (figure 5).

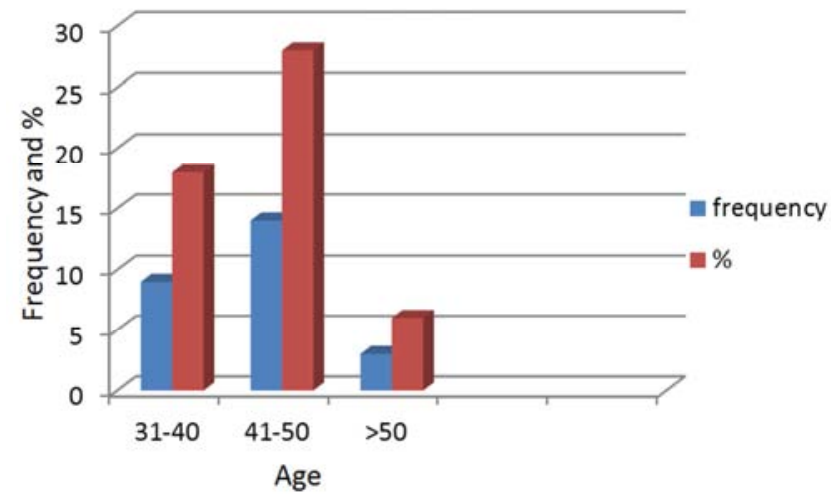

Figure 5. Age distribution of miners.

Surprisingly of the fifty miners only 2 were females (Figure 6). This difference could be because mining is physically taxing and attracts only males. But it is more possible that these parts of country are far away from towns where even now the effect of old customs have not been completely eliminated and women are still relegated to the "home", while it is the responsibility of the male to provide 
to the family. This decreased number of females may mean less direct exposure to them and decreased reproductive effect of poisoning leading to less foetal effect and less number of children affected through breast feeding. Breast feeding is one of the leading causes of infant poisoning from mercury exposed mother. A study found that concentration of total mercury in breast milk from nursing mothers in the Amazon Basin, Brazil, ranged from 0.0 to $24.8 \mu \mathrm{g} \mathrm{kg}^{-1}$ with a mean of $5.8 \mu \mathrm{g} \mathrm{kg}^{-1}\left(v 0.9 \mu \mathrm{g} \mathrm{kg}^{-1}\right.$ in USA). Infants fed milk from these mothers may receive more than $0.5 \mu \mathrm{g} \mathrm{Hg}$ $\mathrm{kg}^{-1}$ body weight (the tolerable daily mercury intake recommended for adults by the WHO) in $53 \%$ of the infants' measured. [16]

However even though women were scarce in the mining sites and this would result in low possibility of direct mercury exposure; they could still be affected indirectly from the environment since they live near the mining sites as is common with the miners families. For example the water they use for their household needs is the same running water that is also used by the miners for their mining activities. Some of the miners claimed that they sometimes process the gold near their living quarter with the help of their wives and children. In this study it was found out that $60 \%$ of the miners were married.

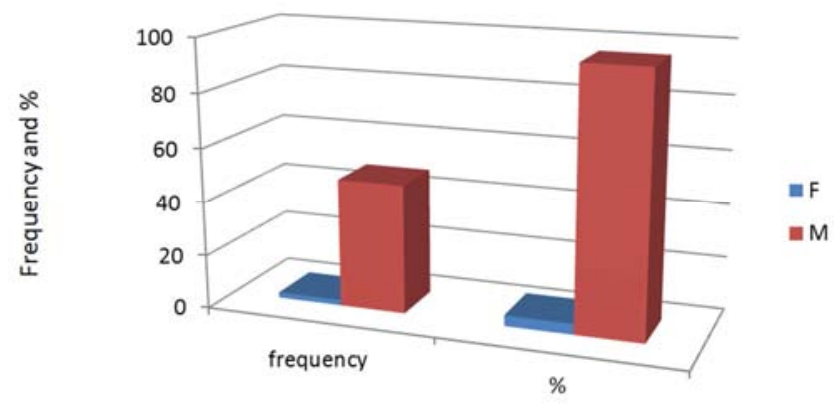

Figure 6. Sex distribution of miners.

Many of the miners had general health complaints that they have felt at one time or another. $6 \%$ of the miners suffered from excessive salivation which can be due to mercury exposure on gastrointestinal tract. Also 4\% explained that they have a chronic headache and $6 \%$ have stress which can be as a result of mercury action on central nervous system. $20 \%$ of the miners told that they apply mercury on blisters as an antiseptic which was similar to the traditional medical use of mercury in the past. One worker claimed that she developed irregularity in her menstruation cycle since she started working in the mines; it may be due to the taxing physical work demanded at the mines or metabolic dysfunction associated with mercury poisoning.

\section{Conclusion}

Although illegal gold mining is a relatively recent development in Eritrea, we can expect an increase in the mining activity along with increased use of mercury in the coming years. This may lead to an exacerbation of the health effects. Mercury poisoning is a dire problem that is escalating in many provinces in Eritrea and unless strict regulations and awareness campaigns are launched by the government it may led to health crisis and social unrest. Various awareness campaigns about mercury poisoning need to be launched since it was seen in our study that majority of the miners have no idea of the consequences of its use. This threat to human health can be contained through alternative mining methods that are not as mercury intensive, although there is little incentive for miners to pursue alternatives since this might require more expensive equipment and processes. Therefore alternative methods that are inexpensive and easy to use have to be searched and offered to the miners.

\section{Limitations of Study}

1. Consideration by the workers as government spy, difficulty in approaching them

2. Some workers could not fill the questionnaire openly feeling insecure about any further consequences.

3. No laboratory setup was available for use to enable conclusive correlation between levels of mercury in the body of miners and their health complaints.

4. There were no recorded cases of mercury poisoning in illegal gold mining in Eritrea which hindered presentation of any study.

5. Lack of transportation and telecommunication access resulted in conducting the research in a very limited time.

\section{References}

[1] Petralia J. F. Gold! Gold! A beginner's handbook and recreational guide: how and where to prospect for gold! San Francisco, CA: Sierra Outdoor Products Company; 1996 P.O. Box 2497.

[2] Merchant B. Gold, the noble metal and the paradoxes of its toxicology, 1998 Biologicals 26, p. 49-59.

[3] Anikin A. V. Gold - The yellow devil. International Publishers; 1983 p. 244.

[4] Ronald eisler. Health risks of gold miners: a synoptic review. Environmental Geochemistry and Health 25: Netherlands: Kluwer Academic Publishers; 2003. p. 325-345.

[5] Sam Gogan. Beyond deforestation: illegal gold mining and human health March 19, 2016 / public policy peru.

[6] The Global Initiative against Transnational Organized Crime. Organized crime and illegally mined gold in Latin America. April 2016. www.GlobalInitiative.net

[7] Greer, J. The price of gold: environmental costs of the new gold rush, The Ecologist 23(3); 1993 p. 91-96.

[8] Swenson, Jennifer J, et al. Gold mining in the Peruvian Amazon: global prices, deforestation, and mercury imports. April 11, 2011.

http://www.plosone.org/article/info\%3Adoi\%2F10.1371\%2Fj ournal.pone.0018875\#pone.0018875-Veiga1 
[9] Human Rights Watch (HRW). Toxic toil: Child labor and mercury exposure in Tanzania's small-scale gold mines. August 2013. http://www.hrw.org/node/118031/

[10] International Labor Organization (ILO): Peligros, Riesgos y Daños a La Salud de Los Niños y Niñas que Trabajan en la Minería Artesanal.Organización

InternacionaldelTrabajo.2005.http://white.oit.org.pe/ipec/docu mentos/cartilla_riesgos_min.pdf

[11] Beyond deforestation: illegal gold mining and human health. University of Maryland School of Public Policy in Peru. March 2016.

[12] Jernelov A, Ramel C. Mercury in the environment. Ambio 1994 23: 166.
[13] Nopriadi, Saam, Z, Amiruddin, R, Afandi, D. The influence of illegal gold mining activities toward health of workers in Kuantan Singingi, Indonesia. International Journal of Science and Research August 2015 4(8).

[14] Human Rights Watch (HRW). A poisonous mix: child labor, mercury, and artisanal gold mining in Mali. 2011http://www.hrw.org/sites/default/files/reports/mali1211_f orinsertWebUpload_0.pdf

[15] Human Rights Watch (HRW). Mali: artisanal mines produce gold with child labor. December 6, 2011. http://www.hrw.org/news/2011/12/06/mali-artisanal-minesproduce-gold-child-labor

[16] Eisler, R. Health risks of gold miners: a synoptic review. 2002. 